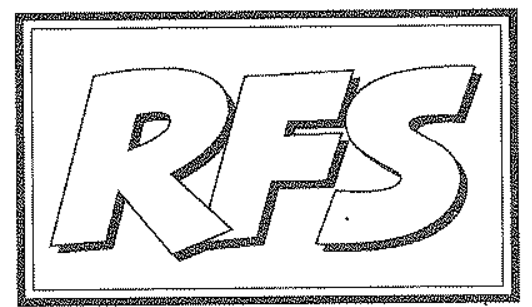

Revista de Fomento Social, 52 (1997), 65-85

\title{
Hacia dónde va la democracia contemporánea
}

Durante el periodo histórico de la llamada «modernidad», los sistemas políticos se han entendido como modelos susceptibles de ser orientados $y$ dirigidos, a través de la razón humana, en tomo a ciertos fines y objetivos compartidos: aunque siempre bajo el papel dinigente de una minoria. Esa visión ha establecido unos nexos implicitos de causalidad entre desarrollo económico y desarrollo político, que hoy aparecen llenos de interrogantes: al mismo tiempo que la propia expansión democrática exige la participación de todos. El conjunto de paradojas y contradicciones de la democracia actual, en un camino sin horizontes definidos, constituye el objetivo del presente artículo.

Antonio J. PORRAS NADALES (*)

(*) Catedrático de Derecho Constitucional. Universidad de Sevilla. 


\section{La crisis}

Aunque quizás se ha exagerado la idea de que la crisis de fin de siglo y la caída de los regímenes del este, vienen a representar algo así como el final de la historia, no cabe duda de que la falta de alternativas globales al sistema mundial ha acabado por producir un cierto ambiente de desencanto o desesperanza. Tras tantas y hermosas construcciones de la historia que nos sugerían un avance imparable de la humanidad hacia la igualdad y la solidaridad, parecemos volver al punto de partida: ese punto que afirma el predominio del interés individual como único y fundamental elemento motor de las sociedades modernas.

La noble convicción de que los viejos ideales revolucionarios de libertad, igualdad, y solidaridad, tendrían una especie de secuencia secular de desarrollo (pasando del sistema del Estado liberal que desarrollóla libertad del individuo, al modelo del Estado social que incrementaría la igualdad, y así hacia un futurible orden de solidaridad en el siglo venidero) se ha caído estrepitosamente por los suelos. El Estado social se bate en retirada, la desigualdad se incrementa precipitadamente (si es que alguna vez ha dejado de hacerlo), y la tragedia de un tercer mundo en plena miseria nos golpea diariamente desde las pantallas. La realidad histórica demostraría nuevamente que igualdad y solidaridad son valores de «segundo orden», frente a la imparable lógica de la propiedad y del egoísmo privado, auténticos motores de orden del mercado.

Por supuesto el factor de mayor relevancia vendría constituido no ya por la caída de los regímenes autoritarios comunistas (que tendrían tan solo el efecto de demostración de que «son posibles» históricamente las alternativas al sistema capitalista), sino por la propia crisis anunciada del Estado Social owelfare state: una crisis generada por los efectos de sobrecarga que el universalismo de las prestaciones, y la creencia de que un Estado poderoso podría atender eficazmente a las necesidades de todos, han producido sobre un sistema institucional que no era al fin y al cabo más que una «rectificación» del modelo de democracia liberal decimonónica. En cierta manera, con la crisis de los regímenes del este y la decadencia del welfare state, parecen desaparecer las grandes opciones «estatalistas» que constituyeron la réplica a la crisis del orden liberal a comienzos de siglo (igual que desapareció hace años la otra opción estatalista, el fascismo).

Como un motor poco potente sometido a un exceso de velocidad o de revoluciones, el Estado Social se ha mantenido en pie vendiendo beneficios

\section{RFS}


sociales a cambio de apoyos electorales, y utilizado la magia del endeudamiento y el déficit público como un sistema para desplazar sobre el futuro la insuficiencia de recursos disponibles (1). Sin embargo, en términos institucionales, puede decirse que no ha habido nada democráticamente «nuevo» en la evolución del Estado social durante el siglo XX: los mismos poderes, los mismos partidos, las mismas elecciones periódicas, la misma ajenidad de la esfera pública, los mismos sistemas limitados de control. La universalización de prestaciones sociales ha permitido efectivamente mejorar «por abajo» situaciones de grave necesidad social (allí donde efectivamente ha tenido éxito), pero en cambio ha producido «por arriba» una competencia desenfrenada entre grupos y colectivos por incrementar sus niveles de bienestar con cargo a los recursos comunes. El gasto público ha caído en un circuito imparable de expansión, por razones a veces puramente automáticas o no inducidas (como el incremento de los recursos sanitarios o tecnológicos, la propia evolución demográfica, etc.). Y no dejan de tener razón ciertas críticas «liberales» al Estado de Bienestar que entienden que la universalización de la cultura de «los derechos» (concebidos como demandas sobre la esfera pública) ha fomentado una especie de seudocultura de la dependencia o del ocio (es más fácil pedir, que conseguir con el propio trabajo), desplazando así las exigencias sociales del esfuerzo, el trabajo o el sacrificio personal. La idea de que un todopoderoso «Estado Padre» vela siempre por nosotros, bloquea los impulsos hacia el estímulo, la innovación, el esfuerzo o la creatividad que han sido una de las claves del desarrollo de la humanidad durante los últimos siglos (2).

Y finalmente esa crisis del Estado social ha acabado por derivar en una crisis

(1) Lo que naturatmente plantea un interrogante de considerable calado: ¿tenemos derecho a hipotecar los recursos de las generaciones venideras a cambio de una mejor atención a las necesidades actuales? ¿tienen nuestros hijos o descendientes algunos «derechos» sobre los recursos actuales que deberíamos tener en cuenta?

(2) Hace unos meses, un Profesor de Derecho Constitucional propuso a sus alumnos en uno de los primeros días de clase un original ejercicio: elaborar entre todos un texto constitucional para una isla desierta a la que se irían a vivir. El panorama resultó absolutamente posmoderno y actualizado: todos tendrían derecho al trabajo, al ocio, a la vivienda, a un medio ambiente digno, a la tutela de la intimidad ante agresiones de la informática, etc, etc. Al terminar el coloquio, el Profesor formuló una pregunta que no había sido respondida: ¿quién y cómo gobernaría la isla desierta?. 
del propio Estado: la mundialización y la globalización de la economía capitalista debilita la capacidad de los poderes públicos -organizados sobre base estatalpara disciplinar y controlar las fuerzas del mercado poniéndolas al servicio de los intereses sociales. Bien es cierto que, hasta ahora, la revisión «neoliberal» del Estado sólo ha impactado con toda su contundencia precisamente en aquellas sociedades donde el propio welfare state tenía un menor desarrollo, es decir, en algunos regímenes del sur y especialmente en Latinoamérica. En cambio, en Europa, aunque elwelfare state no viva sus mejores tiempos, su labor defensiva frente a las deseconomías y efectos negativos del mercado sigue teniendo una indudable vigencia, no sabemos por cuanto tiempo.

\section{Democracia y sistema social}

Esta ausencia de alternativas nos obliga a dirigir la mirada hacia otra dirección: pero cuando definitivamente no hay modelos de referencia en el exterior, parece que sólo nos queda mirarnos a nosotros mismos. ¿Egoísmo, instropección o síndrome del náufrago? Veámoslo: al decir mirarnos a nosotros mismos, queremos simplemente intentar destacar qué hay de valioso, de definitivamente positivo en el modelo llamado «occidental», como para que haya llegado a convertirse en un modelo de referencia al nivel mundial, o como para que merezca la pena ser conservado o mejorado, sirviendo de ejemplo en un contexto de desarrollo histórico universal. Evidentemente lo que hay de positivo, lo que se debe conservar es la Democracia. Seamos realistas: cuando las cosas van mal, lo que en otros tiempos dábamos por supuesto, por ya adquirido, empieza a tener un nuevo valor. Hoy sabemos que crear y, sobre todo, conservar y mejorar un sistema democrático, no es algo que pueda venirnos dado por fuerzas ajenas o superiores. Sabemos que una democracia es una especie de milagro social endógeno que madura y florece en ciertos países a costa de educación cívica, tolerancia, confianza mutua y otras virtudes colectivas. En especial, una democracia que funcione eficazmente, que no se limite a la simple elección periódica de los gobernantes, y que sea capaz de crear un clima de confianza y cooperación, atendiendo a las necesidades colectivas, estimulando el desarrollo social, cultural y económico, y articulando las condiciones de un progreso humano efectivo.

Hoy sabemos, por ejemplo, que la creación de la primera democracia

\section{RFS}


moderna, la americana, fue todo un complejo y difícil resultado del ejercicio de virtudes sociales, de acuerdos y compromisos colectivos, y de respeto mutuo. Algo parecido a lo que sucedió durante la transición española, o recientemente en Sudáfrica. Es una lección importante para enfocar la cuestión del Tercer Mundo. Durante mucho tiempo hemos pensado, primero, que para conseguir la democracia hace falta un cierto nivel de desarrollo económico, y que para conseguir ese desarrollo económico debe eliminarse el circuito de la dependencia impuesto por fuerzas ajenas a los países tercermundistas. En consecuencia, la ausencia de democracia en el tercer mundo ise debería a factores ajenos a la propia población del tercer mundo! En pura teoría de la democracia este planteamiento no es correcto, sino claramente contradictorio: si la democracia es un fenómeno «endógeno», no puede explicarse o interpretarse desde elementos exógenos, y ahí está como demostración el gran fracaso de la descolonización en Africa: ¿por qué aplicar al tercer mundo unos paradigmas distintos a los que, en nuestro propio mundo occidental, explican el surgimiento de instituciones públicas de tipo democrático? La visión correcta nos llevaría, sin embargo, a una construcción algo «dura», que desenmascara algunas de nuestras románticas visiones del Tercer Mundo: ahora habría que pensar que los desastres de las democracias tercermundistas proceden del carácter insolidario de algunas de sus minorías, de la falta de instrumentos suficientes de control de las mayorías, o de la ausencia de una cultura de cooperación colectiva, confianza mutua y educación institucional. Es decir, que en última instancia serían los habitantes del tercer mundo los responsables de su propio y negro destino, como fuimos los europeos los responsables de nuestras guerras mundiales, o los españoles los responsables de nuestra propia guerra civil en 1936. Cada pueblo sería el responsable de su propia historia.

Por supuesto, este es un argumento referido al desarrollo de la democracia, y no a la necesidad de una lucha mundial contra el hambre. Sin embargo, cabría sugerir que el postulado de que el desarrollo económico debe ser considerado como una precondición del desarrollo social y político, que conduce (de un modo más o menos inexorable) hacia la democracia, no es un argumento suficientemente comprobado (o en todo caso, debería ser parcialmente «revisado»). En primer lugar, por una aplicación a la inversa al propio mundo occidental: cuando Alemania, Italia, o algunas otras democracias occidentales cayeron durante el periodo de entreguerras en el fascismo, se estaba incumpliendo este postulado. 
Tanto Alemania como Italia o España eran países relativamente desarrollados conforme a la media de la época, con razonables niveles de educación y cultura en aquel contexto histórico: ¿qué extraña perversión social produjo una decadencia de las instituciones democráticas y el advenimiento de regímenes autocráticos?

Por otra parte, muchos países tercermundistas tienen hoy unos niveles de desarrollo económico o cultural similar al que podían disponer los colonos ingleses de Nueva Inglaterra a finales del siglo XVII: ¿ por qué unos consiguieron poner en marcha instituciones de acción colectiva de tipo democrático y otros no? La idea de que existe una burguesía comercial dependiente del exterior que impide el autodesarrollo institucional y económico no es suficientemente consistente: esos sectores sociales también existieron en países que consiguieron acceder al proceso de desarrollo y consolidación de la democracia.

Por eso, atribuir todos los males del atraso democrático del Tercer Mundo al fenómeno de la dependencia económica es, desde el punto de vista político, una forma de «des-responsabilizar» a los propios pueblos, eludiendo asílas dificultades del aprendizaje de la acción colectiva democrática entendida, repetimos, como un fenómeno endógeno.

Frente a esta construcción tradicional, la teoría social más actual tiende a situar el problema de las precondiciones que deben permitir un desarrollo social e institucional efectivo, en torno al concepto de «capital social», entendido en un sentido cualitativo: es decir, como la generalización de actitudes y hábitos sociales de confianza, cooperación y capacidad para diseñar instituciones de acción colectiva: al estilo de las viejas teorías del apoyo mutuo de Kropotkin. Entiéndase bien: no se trata ya del ejercicio de puras virtudes morales o altruistas «tout court», como la solidaridad o la caridad con los semejantes, sino de la posibilidad efectiva de mejorar las ventajas individuales en un contexto de cooperación con la colectividad, con los otros (3).

El problema de fondo lo detectaba claramente Alexander Bergmann en su magnífico artículo sobre «La 'crisis' y cómo (no) reaccionar ante ella», (4)

(3) Cfr. E. Ostrom (1990), Governing the Commons: The Evolution of Institutions for Collective Action, Nueva York, Cambridge UP. R.D. PUTNAM (1993), Making Democracy Work, Princeton UP.

(4) En esta misma Revista de Fomento Social, n. 50, 1995, p. 191.

\section{RFS}


cuando afirmaba «El 'quark' que plantea quizás más problemas en el terreno social es el vínculo entre comportamientos individuales y colectivos. Estos comportamientos son, sin duda, interdependientes, pero de una manera nunca bien comprendida. A veces se amplifican mutuamente, a veces se oponen». Pues bien, la existencia de nexos constructivos y de cooperación entre iniciativas y comportamientos individuales por un lado, y esferas institucionales de carácter público o colectivo por otro (determinados generalmente a través de pautas de cultura social o política conformadas a lo largo de la historia), constituyen el capital social de un pueblo o una colectividad.

Allí donde tales virtudes sociales tienen unos niveles adecuados de presencia, surgen mejores condiciones para un desarrollo social, político o económico. Y ello dependiendo de los diferentes contextos: por ejemplo, durante años nos hemos preguntado asombrados en el mundo occidental cómo era posible el milagro de los «dragones» del Pacífico sobre la base de una mano de obra en condiciones laborales de semiesclavitud, dentro de marcos institucionales escasamente democráticos; hasta que hemos descubierto que era el sentido familiar de la cultura oriental el que estaba creando una red de solidaridades sociales que operan en la práctica con unos efectos similares a los de nuestra seguridad social pública. Del mismo modo que nos asombramos con frecuencia ante al auge del fundamentalismo islámico sin comprender que, en determinados contextos, puede tratarse de un intento de crear un orden social estable enfrentado a situaciones de descomposición social y moral.

\section{¿Democracia de Partidos o democracia insuficiente?}

Ahora bien, suponemos -acaso desde una perspectiva egocéntrica y occidental-que tales aptitudes sociales tienen unos modelos «óptimos» de plasmación en torno al concepto conocido de Democracia representativa, cuyo mayor desarrollo histórico ha tenido lugar hasta ahora en algunos países del Norte. Esta es la razón de que debamos mirarnos a nosotros mismos. Y debemos hacerlo porque -ahora sí- parece que no estamos satisfechos con los niveles de rendimiento de esta democracia, en relación con sus propias potencialidades, o con las expectativas que razonablemente cabría depositar en sus instituciones.

Son dos las dimensiones generales en que se proyecta este problema, y que podríamos resumir en torno al doble sentido del concepto de libertad: la libertad 
negativa y la libertad positiva. La primera, la libertad «negativa», hace referencia a los derechos y libertades (es decir, libertad frente al poder), y su línea de desarrollo conduce a una progresiva internacionalización de los ámbitos de imputación y garantía de los derechos humanos: las Declaraciones internacionales de derechos, los tribunales internacionales, y algunas ONGs, constituyen probablemente la punta de lanza de este proceso expansivo, que reflejaría sin duda la más hermosa generalización de los valores propios del mundo occidental a todo el planeta; de ahí que los derechos fundamentales (construcción jurídica forjada originariamente en el constitucionalismo occidental) se hayan convertido finalmente en derechos humanos. Aunque naturalmente, ese movimiento internacional exige igualmente la presencia de claves internas que deben asegurar una garantía efectiva de los derechos humanos: claves que dependen fundamentalmente de la existencia de circuitos judiciales con capacidad para ejercer un control efectivo sobre los propios gobernantes.

El cuanto al segundo ámbito, el de la libertad «positiva», hace referencia en cambio al aspecto institucional, es decir, a la capacidad de los aparatos y órganos estatales para satisfacer efectivamente las demandas ciudadanas y para resolver los problemas y necesidades colectivas, contando con la presencia activa de los propios afectados (o sea, libertad para participar, para dirigir y para orientar el poder). Se trata pues de dos ámbitos relativamente disociados: es decir, países con un razonable grado de protección de los derechos humanos pueden poseer instituciones escasamente eficaces, y viceversa.

Sería más bien en este segundo ámbito, el institucional, donde afirmamos que no ha habido avances o innovaciones sustanciales desde la aparición del modelo de la Democracia Liberal en el siglo pasado. En general, se trata de un modelo que ha sido interpretado desde una óptica que podríamos calificar como «mecanicista»; es decir, una visión según la cual las necesidades y demandas ciudadanas se expresan consistentemente por vía electoral a través de las urnas, se transmiten así a los partidos políticos y al Parlamento desde donde, a través de la mayoría, se convierten en las políticas o programas de actuación del gobierno y la administración. Todo ello en el marco de unas orientaciones finalistas generales recogidas en los propios textos constitucionales.

Habría pues un circuito unificado (político) de comunicación entre sociedad y Estado, controlado fundamentalmente por los partidos, desde el cual las

\section{RFS}


demandas ciudadanas se traducen en respuestas de la esfera pública. A mayor nivel de demandas correspondería un mayor volumen de respuestas: el intervencionismo público, en crecimiento casi constante a lo largo del siglo XX, demuestra efectivamente la presencia de una notable sobrecarga (la propia del Estado de Bienestar) en el volumen de «respuestas» o de actuación de la esfera pública. Sin embargo el circuito de expresión de «demandas» (es decir, el voto) no ha experimentado expansión ninguna desde la generalización del sufragio universal a comienzos de siglo: los ciudadanos tienen hoy la misma cuota de participación política que tenían ihace sesenta o setenta años!; es decir, una papeleta cada cuatro años.

El desajuste entre uno y otro circuito (la famosa «crisis de legitimación» del capitalismo tardío, de que hablaba Habermas hace ya más de veinte años) ha sido asumido en la práctica por los partidos políticos, que han visto incrementada enormemente su capacidad configurante sobre el conjunto del sistema: de ahí que el modelo que conocemos como Estado Social podría ser calificado, acaso con mayor propiedad, como Estado de Partidos. Son los partidos los que de hecho expresan y concretan las demandas ciudadanas en sus respectivos programas (o sea, la oferta que condiciona la demanda), los que protagonizan las campañas electorales y los que finalmente controlan el poder. El problema es que los distintos partidos compiten entre ellos, primero y fundamentalmente para eso, para conquistar el poder; y sólo una vez conquistado el poder a través de la mayoría, podrá en su caso enfrentarse la tarea de generar respuestas eficaces a las necesidades colectivas. ¿Cuál de los dos momentos predomina: el «electoral-competitivo» para conquistar el poder y mantenerse en el mismo, o el «programáticointervencionista» para ejercerlo en beneficio de todos?

No es ningún secreto que las democracias occidentales vienen experimentando desde hace tiempo una tendencia al «electoralismo partitocrático», que se refuerza debido a la escasa capacidad de control ciudadano para hacer cumplir los programas electorales, lo que contribuye a acentuar la autonomía de la política (y de los políticos): incluso en la hipótesis «ideal» de que el programa electoral fuera una expresión consistente de las demandas de todos, y no un mero instrumento seductivo de la oferta electoral destinado simplemente a permitir «ganar» las elecciones (como suele ocurrir con frecuencia). En consecuencia, si los elementos objetivos o materiales de la relación electoral parecen carecer 
de un grado suficiente de eficacia (5), cabe suponer que los que se refuerzan alternativamente serán los elementos «subjetivos», es decir, los referidos a la elección de las personas. O dicho en otras palabras, que el circuito de la representación política no parece ser el mecanismo más adecuado para asegurar una proyección consistente y unificada de las demandas de todos hacia la esfera pública, sino más bien un mecanismo legitimador para designar a los gobernantes. Se responde así consistentemente a la cuestión de Quién gobierna, pero no a la de en Qué o Cómo debe concretarse y realizarse la acción de gobierno.

\section{La Democracia deconstruida (o la muerte del «Bríncipe» de Maquiavelo)}

Por lo tanto, habría que concluir provisionalmente que nuestra «visión» de la democracia competitiva de partidos no se corresponde realmente con lo que ésta ES en realidad. La tradicional visión «mecanicista», que entiende el proceso democrático como un gran circuito comunicativo unificado, donde las demandas ciudadanas se traducen en respuestas políticas del Estado, sería en realidad una mera construcción ideológica procedente del pasado, que se mantiene a símisma por pura inercia sin tener en cuenta las transformaciones en marcha.

Frente al gran protagonismo condicionante de los partidos, el ciudadano de a pie, considerado como mero elector, no tiene otra opción que asumir una posición generalmente pasiva, plebiscitaria, o de simple espectador de la política (6). O en su

(5) Y no ya porque los propios partidos actúen negligentemente a la hora de aplicar el respectivo programa en su acción en gobierno, sino porque, de hecho, la labor de gobierno tiene características funcionalmente «autónomas» que no se ajustan fácilmente a la aplicación mecanicista de un «programa»: en efecto, todo gobierno se ve condicionado en su actuación por un cúmulo de factores exteriores, problemas coyunturales sobrevenidos, estrategias de negociación con agentes sociales de resultados no previsibles, pactos con otros partidos, etc. De tal forma que en la práctica es imposible concebir la acción de gobierno como una «emanación» coherente de respectivo programa electoral. Cfr. sobre el tema A. Porras NADALEs (1994), Representación y democracia avanzada, Madrid, Centro de Estudios Constitucionales

(6) Lo que por cierto no puede considerarse exclusivamente como un problema de la democracia contemporánea, sino como algo ya implícito en los mimos momentos fundacionales. Como ha destacado Hannah Arendt, comentando los origenes «republicanos» de la tradición democrática de la revolución americana, el propio Thomas Jefferson tenía «un presagio de lo peligroso que podía ser permitir al pueblo compartir 
caso, cuando consigue una posición activa a través de grupos y colectivos sociales organizados, la orientación dominante será la de intentar proyectar sus demandas directamente sobre la esfera de la administración pública, siguiendouna lógicade tipo «corporatista»; es decir, al margen del circuito político-representativo. ¿Para qué sirven entonces las elecciones? Evidentemente, para determinar legítimamente Quién debe gobernar, pero muy escasamente para concretar en Qué debe consistir la acción de gobierno o Cómo debe implementarse efectivamente.

Esta «deconstrucción» de la realidad de las democracias nos exige de forma inmediata un intento de reconstrucción de la mismas. Siguiendo una de las más sugestivas elaboraciones, la de Niklas Luhmann, cabría entender que la principal novedad de las democracias contemporáneas sería la inexistencia de un (único) centro (político) capaz de unificar racionalmente el conjunto de la actuación de la esfera pública; o sea, que se ha producido un cierto «vacío funcional» del centro político del sistema, el cual, aunque sigue apareciendo como núcleo de imputación legítima, en realidad carece de una fuerza real de dirección racional y unificada del conjunto del proceso representativo (7). Probablemente no se ha destacado suficientemente la trascendencia de esta nueva visión de las cosas: según la teoría del vacío funcional del centro, toda actuación instrumental del gobierno (el «centro») intentando mantener las anteriores pautas mecanicistas, debería entenderse como una patología funcional; por lo tanto el control de la política, de la administración, el mantenimiento de circuitos clientelares, el control-manipulación sobre la opinión pública, y en definitiva todo aquello que desde Maquiavelo consideramos como consubstancial al poder político, debería ser considerado ahora en realidad como un conjunto de disfunciones, patologías, o síntomas evidentes de una tendencial «corrupción» del sistema (8).

el poder público sin proporcionarle al mismo tiempo más espacio público que la urna ni más oportunidad de hacer oír su voz en público que la jornada electoral. Comprendía que podía ser un peligro mortal para la república que la Constitución otorgara todo el poder a los ciudadanos sin darles la oportunidad de ser republicanos y de actuar como ciudadanos». Cfr. sobre el tema M. Vatter «La democracia entre representación y participación» en A. Porras NADALEs (ed.) (1996), El debate sobre la crisis de la representación política, Madrid, Tecnos.

(7) Cfr. su Teoría política en el Estado de Bienestar, trad. cast. Alianza, 1993.

(8) Cfr. sobre el tema A. Porras NADAles (1988), Introducción a una teoría del Estado Postsocial, Barcelona, PPU. 
Frente a este «vacio del centro», aparecerían al menos cuatro esferas diferenciadas y relativamente autónomas: la política, la administrativa, la jurídica y la de la opinión pública. Cada una de ellas tendría sus propios objetivos finalistas, sus propias pautas de actuación, sus propios criterios de racionalidad, y en definitiva su propia «autoreferencialidad», pudiendo mantener relaciones diversas y complejas con las restantes esferas. Por ejemplo, no deben caber muchas dudas de que algunas de las más recientes revisiones críticas del propio sistema se han producido precisamente por una interconexión directa entre el circuito de la opinión pública y sus medios de comunicación, con el sistema jurídico-judicial encargado del control jurisdiccional. Así ha sucedido en Italia y puede estar sucediendo en parte, en España.

Esta pluralidad de ámbitos públicos de imputación y de decisión afectaría también desigualmente a la constelación de intereses sociales con capacidad para influir sobre cada uno de esos sectores de la esfera pública: unos intereses que ahora sufrirían un proceso de fragmentación y diversificación en un marco de progresiva complejidad. Esta palabra, «Complejidad», resulta ser precisamente la noción clave que se maneja ante la nueva realidad: Io que significa en sentido inverso que ya no es posible concebir a las democracias como sistemas dotados de una dirección u orientación unificada; la crisis del orden racional de la Modernidad se ha trasladado también a la concepción de la política (9). Por supuesto, hay que recordar que las Constituciones siguen conteniendo un complejo de cláusulas finalistas o sistema de valores, a los que debemos considerar como fundamentales: pero nadie piensa realmente que la política tenga como misión «aplicar» esos valores (entendiendo «aplicar» en un sentido mecanicista riguroso), sino tan sólo operar libre y flexiblemente dentro de los mismos; es decir, que se trata de «valores marco» que se limitarian a definir de una forma abierta el conjunto de posibilidades legítimamente toleradas dentro del sistema. En

(9) Lo que se refleja por ejemplo en la sugestiva definición de la democracia de Giuseppe di Palma: «an open and open-ended game that imposes no expectations on its players, except that they play». Es decir, un sistema abierto, y con fines u objetivos abiertos. Chr. G. Dr Palma, «Democratic Consolidation: A Minimalist View», Conferencia sobre «Parliaments and Democratic Consolidation in Southern Europe», Fundación J. Bofill, Barcelona, 1987. 
definitiva, bajo el reinado de la diversidad y la complejidad posmoderna se ha producido la desaparición de los fines unitarios y globales del Estado: el Príncipe de Maquiavelo ha sido descabalgado de su trono.

Toda esta deconstrucción compleja y posmoderna de la democracia política puede resultar muy sugestiva al nivel intelectual, pero lo importante es: $i$ se avanza con ello hacia una democracia más eficiente, hacia una mejor resolución de los problemas sociales? o en otra palabras ¿seguimos los occidentales en condiciones de poder ofrecer un «mejor modelo» en orden a la configuración institucional de la acción y la cooperación social?

\section{Navegando ex la complejidad}

Para intentar responder a esta pregunta no tenemos más remedio que avanzar, al menos provisionalmente, en esa complejidad, y más en concreto en torno a las esferas de la política y de la administración, que son precisamente los grandes circuitos de «respuesta» a las demandas sociales.

A) Por supuesto la esfera política (en sentido estricto: es decir, la mayoría que controla el gobierno) debe seguir manteniendo una cierta capacidad de orientación general sobre la actividad del Estado: sólo que ahorala «orientación» habría que entenderla más en un sentido genérico, macro, o legitimador, que en un sentido mecanicista riguroso, en cuanto determinación exacta del conjunto de respuestas que la esfera política debe dar a las necesidades sociales (10). Ya sabemos además que la forma de actuación de la política requiere una priorización de las estrategias electoralistas que deben asegurarle la permanencia en el poder: aunque al mismo tiempo, es ese mecanismo electoral el que conforma el soporte de legitimación global del sistema, la cuestión de Quién gobierna.

En su desarrollo histórico concreto, esta situación ha acabado dando lugar (en las sociedades desarrolladas) a la formación de las denominadas «mayorías satisfechas»(11); mayorias que reciben un cierto grado de beneficios del

(10) Cfr. sobre esta cuestión, Antonio J. Porras Nadales «Modelos de representación y formas de gobiemo», en G. Ruz-Rico, S. Gambino (coord.) (1997), Sistema electoral y formas de gobierno: la experiencia italiana y española, Valencia, Tirant lo Blanc.

(11) Cfr. John K. Galbrarth (1992), La cultura de la satisfacción, Barcelona, Ariel. 
mercado o de las prestaciones públicas (por lo tanto, según una lógica clientelar), o bien que mantienen su lealtad en base a circuitos de legitimación de tipo publicitario (la denominadavideopolítica, basada en la proyección de la imagen), con escaso grado de información, crítica y participación ciudadana efectiva. Por lo tanto, son mayorías en general reacias a cualquier tipo de sacrificios en beneficio de la minoría excluida (12), y que se constituyen como un instrumento esencial para asegurar la autoreproducción del oligopolio de partidos que conforma el mercado político. En este contexto, parece que la esfera política se limitará simplemente a intentar mantener su hegemonía a cambio de convivir con el conformismo, el clientelismo y la manipulación más o menos indirecta de la opinión pública, renunciando al mismo tiempo a una auténtica dirección racional y unificada de la realidad. Aunque, naturalmente, siga aportando el gran circuito de legitimación política del sistema, a través de las elecciones. O sea, el viejo «Príncipe» se mantiene en el trono, a cambio de renunciar a su posibilidad efectiva de gobernar o transformar la realidad.

B) Pero nos queda la otra esfera, que podemos denominar como la administrativa (13), aquella que está experimentando un proceso más consistente de expansión con el desarrollo del intervencionismo, y al mismo tiempo mayores cambios al nivel cualitativo. Es la que deberá asumir de forma más consistente la exigencia de responder a la necesidades concretas o demandas sociales, de una manera eficaz e inmediata. Si aceptamos como lógica la hipótesis del «vacío funcional del centro», habría que entender que el centralismo verticalista que presidió la evolución del Estado intervencionista hasta los años setenta, está siendo sustituido por un apogeo de la «periferia», vinculado al desarrollo del regionalismo, el municipalismo oel autonomismo: un tipo de esfera pública más próxima a los ciudadanos y en consecuencia, al menos en principio, más

(12) Lo que, de ser correcto, vendría a echar por los suelos todas las construcciones de la Historia basadas en la «lucha de clases», donde una minoría dominante explota a una mayoría oprimida ( $y$ donde en consecuencia, un exceso de opresión conduce al umbral de la revolución): ahora por el contrario, serían las mayorías satisfechas las que, de forma democrática, podrían permitirse el lujo de prescindir de la minoría excluida.

(13) Aunque en la literatura se prefiere más bien utilizar en este campo el concepto de «policies» (políticas públicas) para diferenciarlo de la politics (o política en sentido tópico) e incluso de la polity (o esfera institucional). Cfr. sobre el tema J. SubiRAts (1989), Análisis de políticas públicas y eficacia de la Administración Madrid, MAP.

\section{RFS}


permeada por la presencia directa de los intereses sociales (14).

Habría dos tipos de transformaciones sustanciales en este ámbito: en primer lugar una de tipo estructural u organizativo, con la aparición de organismos institucionales semiautónomos o semiindependientes, generalmente dotados de presencia directa de organizaciones sociales y ciudadanas (15), y por lo tanto escasamente vinculados a la tradición mecanicista-verticalista de la «burocracia» (entendida como mero instrumento pasivo al servicio de las directrices procedentes de la política). En segundo lugar, aparecerían otras transformaciones de carácter más bien funcional, dando lugar a lo que se conoce como «administración adecuada a consensos», lo que implica en consecuencia que la esfera pública debe otorgar un nuevo papel activo a los ciudadanos (identificados ahora como clientes o usuarios) tanto en el diseño de las diferentes políticas públicas como en su proceso de implementación y control.

Puede entenderse que es en este circuito periférico donde se están produciendo los más importantes fenómenos de innovación democrática, implicando ahora sí- una mayor presencia de los ciudadanos en todo el proceso de la actuación pública. Aunque con una importante salvedad: que esta transformación se opera en ámbitos fragmentarios más o menos delimitados o dispersos, implicando en consecuencia una notable diversidad en las respuestas públicas (conforme al principio de que la auténtica igualdad debería consistir en un tratamiento diferente de situaciones objetivamente distintas); o sea, confirmando la segunda «ley» de la termodinámica, la democracia parece desarrollarse generando cuotas crecientes de complejidad o entropía.

Pero en cambio, ahora deberíamos destacar aquí, rotundamente, un importante hallazgo de la democracia: la constatación de que las posibilidades de consenso son mayores en ámbitos sociomateriales limitados. Es decir, que la microdemocracia es «mejor democracia»: trabaja sobre el consenso y no sobre el conflicto, al mismo tiempo que asegura mayores cuotas de participación y de eficacia final en sus respuestas. De ahíla importancia del llamado «capital social», proyectado generalmente en esferas de tipo regional o subnacional: los ámbitos socioculturales abiertos, participativos, responsables y solidarios, asegurarán un mejor

(14) Theodore J. Low: (1978), The End of Liberalism, Nueva York, Norton.

(15) En la literatura se les ha dado denominaciones originales: QUANGOS (Quasi nongovernmental organizations), o PIGS (Private Interests Governments). 
funcionamiento institucional de la acción pública democrática, permitiendo una más adecuada identificación de necesidades y una respuesta más eficaz a las mismas.

Todo ello siempre y cuando la esfera clásica y tópica de «la política» sepa asumir ordenadamente su responsabilidad de «self-restreint», limitándose a sus tareas de legitimación y de orientación «general» del sistema (16): lo contrario significaría entrar en circuitos funcionalmente patológicos, en fenómenos de colonización de la política sobre pautas de vida socialmente establecidas (en la expresión de Habermas), entrando así en la antesala que conduce al proceloso abismo de la corrupción.

El resultado natural de este proceso será, por ahora, una tendencia a la mayor concretización o singularización del intervencionismo público y de los propios instrumentos jurídicos que sirven a la acción del Estado (17).

\section{Nuevos descubrimientos, nuevos riesgos}

¿Merece la pena adentrarse, sin miedo a potenciales riesgos, en esta nueva oleada histórica, basada en las formas propias de la «microdemocracia», inspirada en la participación y el consenso, y adecuada a un contexto de diversidad y fragmentación? ¿Sigue siendo éste el «mejor» modelo, el más avanzado, el que nuevamente occidente puede ofrecer como paradigma al nivel mundial? Hay algo en primer lugar que nos produce cierta sorpresa o perplejidad: y es que ya no sería posible detectar una «orientación» unificada o concreta de los sistemas políticos y por lotanto de las colectividades (18). Podremos caminar conjuntamente, democráticamente, pero sin saber exactamente hacia dónde. En todo caso, cabría aceptar que ahora ya no va a haber un Príncipe soberano, una minoría «iluminada» o una élite dominante (incluso democráticamente elegida,

(16) Cfr. Amy GUTMANN (ed.) (1988), Democracy and the welfare state, Princeton UP.

(17) Cfr. una clarividente descripción del nuevo tipo de derecho que se generaría en este contexto postintervencionista en: Andrés GARCiA INDA, «La regulación del voluntariado en el contexto de las transformaciones jurídicas del Estado Social», en esta misma Revista de Fomento Social, $n^{\circ} .50,1995$, pp. 493-514.

(18) Al menos, mas allá de las tendencias difusas que, condicionadas por la competencia propia del mercado político, pueden expresarse a través de las urnas. 
por supuesto) que decida por todos nosotros. Decidimos todos conjuntamente, pero no hay un piloto que gobierne la nave: el camino recorrido sólo podemos saberlo mirando hacia atrás, como decía el poeta.

A esta incertidumbre se añade la presencia de evidentes riesgos: en primer lugar, el riesgo de que esferas institucionales fragmentadas o de carácter micro tengan evidentemente un menor «poder» para enfrentarse a las grandes organizaciones multinacionales privadas. Cabría incluso sugerir que, en este contexto, los grupos económicos poderosos pueden llegar a colonizar o «capturar» esferas institucionales concretas: los «poderes privados» acabarían así predominando sobre los poderes o instituciones públicas, que representan los intereses comunes.

Aunque también cabría pensar que ese riesgo, en realidad, ha existido siempre. Y frente al mismo sólo cabría oponer lo que ha dado en denominarse como «autoreferencialidad» del sistema jurídico: es decir, puesto que toda acción pública está regulada en normas jurídicas (en principio válidas y aceptadas por todos), de lo que se trata es de evitar que ese derecho regulativo, que establece las reglas de juego, sea «colonizado» por intereses segmentados o parciales: lo que, entre otras cosas, se consigue mejor asegurando la participación de «todos» en los consensos básicos que deben servir de soporte a tal derecho (19).

Sin embargo, hay un segundo riesgo probablemente aún mayor, que consistiría en la posibilidad de que todo ese entramado de fragmentación y de complejiclad en que se mueve la democracia «posmoderna» acabe al final siendo un simple reflejo del sistema de los «egoísmos colectivos», donde cada sector, cada comunidad, cada ámbito de intereses, o cada esfera sociojurídica, se limite a ser expresión de la pretensión de cada uno de ellos por maximizar su porción de la renta social disponible: su trozo de la tarta. O sea, que del «egoísmo privado» del primitivo liberalismo habríamos pasado al «egoísmo social» de los grupos organizados de nuestras sociedades pluralistas; con lo cual resultaría que al final los mejor organizados, los más influyentes o los más poderosos, acabarían

(19) A lo que se añade, desde una perspectiva técnico-jurídica, la propia labor autodefensiva que realiza la denominada «dogmática jurídica» o conjunto de principios y técnicas propias del derecho, que lo hacen -en principio- relativamente inmune a interferencias extrañas procedentes del exterior. 
obteniendo ventajas a costa de los otros. Es probable que algo de esto esté ya sucediendo.

$Y$ es aquí donde aparecería ahora el nuevo sentido de la solidaridad, lo que algún autor ha denominado como «racionalidad reflexiva» (20), o conciencia reflexiva: una forma de conciencia colectiva que se traduciría en la necesidad de que cada ámbito, cada sector, cada grupo, cada esfera social autónoma, «tenga en cuenta» los efectos externos de sus acciones antes de ponerlas en práctica, permitiendo así el surgimiento de un marco interactivo horizontal, solidario y relativamente armónico. Todo ello con el objetivo de asegurar que la interacción entre lo singular o lo individual, no resulte perturbador, sino más bien funcional, en relación con el conjunto de la colectividad.

Esto último puede parecer una sofisticación, una manifestación quintaesenciada de la «cultura» (occidental) en su más noble sentido, algo sólo al alcance de élites muy ilustradas: pero se entenderá más simplificadamente si comparamos ese concepto de la «conciencia reflexiva» con lo que podemos considerar como la más trascendental novedad en la evolución de las mentalidades colectivas del siglo XX, el desarrollo de la «mentalidad medioambiental». La conciencia ecologista o medioambiental, cuya expansión en el mundo puede calificarse de fulgurante, supone precisamente esa exigencia de «tener en cuenta» en cualquier tipo de acción, de actividad económica, empresarial o profesional, los efectos externos de nuestras propias acciones; es una mentalidad que ha generado, o está generando toda una «cultura» planetaria que nos obliga a mirar al medio exterior con mayor cuidado (21).

La consideración del medio externo, o del ambiente exterior, no solamente como un medio ambiente «físico», sino igualmente de tipo social o institucional, derivaría pues hacia esa dimensión social de la «conciencia» o «racionalidad reflexiva», entendida como un instrumento adecuado para superar el riesgo de

(20) Gunther Teubner (1983), «Substantive and Reflexive Elements in Modem Law», Law \& Society Review, $\mathrm{n}^{\circ} .17,2$, pp. 239-285. G. Teubner (ed.) (1986), Dilemmas of Law in the Welfare State, Berlin, Walter de Gruyter.

(21) Y podríamos decir que supone al mismo tiempo una réplica frente a los grandes desafíos de la vieja Modernidad, tanto frente a aquel slogan marxista de la «apropiación de la naturaleza por el hombre», como frente al ideal de una racionalidad sustantiva o superior capaz de englobarlo y de dirigirlo todo. 
los egoísmos colectivos, y generadora al mismo tiempo de un marco interactivo de solidaridad horizontal. Horizontal, en el sentido de que surge de la propia interacción colectiva: no es dirigida ni controlada por nadie en concreto.

La pregunta final sería: ¿es posible? Es decir ¿es posible que todo proceso de decisión pública al nivel micro, en un contexto interactivo o participativo de carácter democrático, pueda ser capaz de «tener en cuenta» los efectos externos o las consecuencias de su actuación -fundamentalmente en forma de recursos disponibles y de impacto resultante-, como un factor condicionante de su propia decisión? De entrada habría que decir que, como mínimo, es difícil, entre otras razones por la misma disponibilidad de información o deconocimiento. Hablamos de un «conocimiento» acerca de cuáles son esos efectos externos de las acciones de cada cual: cuando un deteminado colectivo, en base a su propio sistema de necesidades, formula una demanda que debe impactar sobre el conjunto de los recursos públicos (o sea, sobre el presupuesto el Estado), generalmente no sabe cuáles son exactamente esos recursos públicos, qué tipo de impacto genera o qué tipo de limitaciones pueden existir. Los costes difusos nunca son fácilmente percibidos.

En realidad, una de las claves en base a las cuales los políticos han ejercido el monopolioefectivo de la política era precisamente su (supuesta) disponibilidad de un tipo de conocimiento o de información que no estaría al alcance de los ciudadanos, exigiendo en consecuencia unos circuitos decisionales autónomos o separados. Ahora bien, si hay actualmente algún tipo de revolución que esté impactando de forma inmediata en este campo es precisamente la revolución de las informaciones a través de la cibernética y las autopistas de la información. Es decir, que la información, el conocimiento, existe. A veces está muy cerca, en las mismas Universidades o Institutos de investigación: son también elementos del propio «capital social» de los que puede disponerse como se dispone del capital en los mercados financieros. El conocimiento socialmente útil y socialmente disponible debería pues poder incorporarse fácilmente a los procesos de decisión pública, como una especie de $\mathrm{I}+\mathrm{D}$ de dimensión socioinstitucional, aportando no ya sólo información, o datos brutos, sino auténticos elementos que sirvan de soporte a una racionalidad reflexiva.

El desarrollo de esa conciencia reflexiva y la disponibilidad de instrumentos de información y conocimiento, constituirían pues los mecanismos idóneos para enfrentar, desde la diversidad y la fragmentación, los riesgos de esta «mejor» 
democracia convertida eventualmente en un modelo susceptible de proyectarse nuevamente en una dimensión planetaria.

\section{Conclusiones menores}

La idea resultante sería pues que, en un contex to de complejidad y de apertura democrática a la diversidad y el pluralismo (donde la esfera política debería ir renunciando a su pretensión de dirigismo y de control sobre el conjunto del sistema), cada sector social, cada esfera institucional, cada agrupación de intereses, debería ser capaz de generar una conciencia reflexiva que permita preverel impacto general de sus propias actuaciones sobre el conjunto: utilizando para ello todo el sistema general de información y de conocimiento disponible. Este sería el nuevo y original marco constructivo en que se proyecta el sentido contemporáneo de la solidaridad, entendida como un circuito de desarrollo expansivo e innovador de la propia democracia.

Tal conclusión no resulta ser pues especialmente original, ni está dotada de ningún tipo de proyección revolucionaria: no detecta grandes y nuevos horizontes de referencia, ni será capaz de movilizar utópicamente a las masas. No afectaría a la Historia con mayúsculas, sino a las pequeñas y cotidianas historias de cada día. Aunque creemos que es efectivamente el resultado de una visión endógena o instrospectiva de nuestra propia realidad: una visión que puede responder ciertamente al síndrome del náufrago (el sálvese quien pueda, con sus propios recursos), pero en la certeza de que todos y cada uno tienen su propia tabla de salvación (su propio «capital social»).

Es dudoso incluso que estemos caminando de forma consistente y generalizada en esa dirección, entre otras razones porque, como sugería Alexander Bergmann (22), es posible que la crisis aún no haya tocado fondo: lo que nos situaría más bien en una dimensión futurible y un tanto incierta. Aunque parece que quienes se adaptan con cierto éxito a la crisis lo hacen desde esa perspectiva: aunque ya no se suele citar en los textos el viejo modelo de las democracias nórdicas como ejemplos consistentes del auténtico welfare state, a veces se olvida que esos países están amortiguando con éxito el impacto de la crisis precisamente haciendo derivar sus políticas públicas hacia la esfera local o

(22) En art. cit. en esta misma Revista de Fomento Social, n'. 50, 1995. 
regional, es decir, hacia la periferia del sistema.

Por supuesto podría aceptarse entonces que, efectivamente, hemos llegado al fin de la Historia, o al menos al final de una determinada visión de la historia entendida como un horizonte llimitado de progreso, consumo y bienestar creciente para todos, bajo la dirección (racional) de una minoría iluminada. Cabría aceptar incluso, como propone Anthony Giddens (23), que una de las principales tareas a las que deben enfrentarse los pueblos pobres de la Tierra será la de conformarse con su propia pobreza, gestionarla dentro de límites tolerables, adecuar sus recursos endógenos a su propio sistema de necesidades, y aprender así a ser un poco más felices y responsables con sus propios y limitados recursos.

Sin saber hacia adonde caminamos, no nos damos cuenta probablemente de la importancia de nuestros hallazgos: hemos derrocado al Príncipe de Maquiavelo, y ahora sólo nos quedaría eliminar a todos sus fantasmas.

(23) Cfr. A. Gubens (1996), Más allá de la izquierda y la derecha. Barcelona, Cátedra. 